\title{
Numerical Investigation of a Premixed Combustion Large Marine Two-Stroke Dual Fuel Engine for Optimising Engine Settings via Parametric Runs
}

\author{
Christoforos Mavrelos ${ }^{1}$ and Gerasimos Theotokatos ${ }^{1 *}$ \\ *Maritime Safety Research Centre, Department of Naval Architecture, Ocean and Marine \\ Engineering, University of Strathclyde, 100 Montrose Street, Glasgow, G4 0LZ, Scotland, UK \\ * Corresponding author. \\ 1 These authors contributed equally to this work.
}

\section{ABSTRACT}

As the environmental regulations have become more stringent, the shipping industry has been focusing on more efficient and environmentally friendly means of propulsion and electric power generation. In this respect, dual fuel engines, which operate either in diesel mode or dual fuel (DF) mode by burning diesel fuel or natural gas and pilot diesel fuel to initiate ignition respectively, has become one of the most promising solutions as their dual fuel operation leads to reduced nitrogen oxide (NOx), carbon dioxide $\left(\mathrm{CO}_{2}\right)$, as well as almost elimination of particulate matter (PM) and sulphur oxide ( $\left.\mathrm{SOx}\right)$ emissions. The present study focuses on the comprehensive investigation of a large marine two-stroke dual fuel engine of the low gas pressure concept by using the GT-Power ${ }^{\mathrm{TM}}$ software. Appropriate combustion, scavenging, heat transfer and friction models were used to fully represent the engine performance and emissions characteristics whereas a knocking model was employed to characterise the engine abnormal combustion. The simulation results were initially validated against the manufacturer data and subsequently, the entire engine envelope in both operating modes was simulated. The derived results were used for analysing and discussing the engine operation, performance and emissions as well as for comparing the two operating modes in terms of the turbocharger matching. In addition, a parametric investigation was performed in the dual fuel mode and the results were used for identifying the settings that can further optimize the engine operation in terms of $\mathrm{CO}_{2}$ and $\mathrm{NOx}$ emissions tradeoff. The results indicate that the $\mathrm{CO}_{2}$ and NOx emissions can be simultaneously reduced; however, the 
engine optimisation in the high load region is challenging due to the permissible cylinder pressure constraint.

Keywords: dual fuel premixed combustion, two-stroke engine, simulation, performance and emissions, engine knocking, engine optimisation.

\section{Highlights}

- A large marine two-stroke DF engine of premixed combustion was modelled

- The engine steady state performance/emissions were thoroughly investigated

- A parametric investigation was conducted for optimising the engine DF operation

- Potential simultaneous reduction $\mathrm{CO}_{2}$ and $\mathrm{NOx}$ emissions is possible

- Optimisation at high loads is challenging due to firing pressure restrictions 


\section{INTRODUCTION}

Stringent environmental regulations have been implemented in the last decade by the involved international and national regulatory bodies to control the shipping $\mathrm{NOx}$ and $\mathrm{CO}_{2}$ emissions as well as the fuel sulphur content and consequently, the related SOx emissions. Following the examples of the automotive and power generation industries, there is a strong indication that the future regulations will adopt stricter limits and will include additional pollutants (CO and PM). In this respect, Liquefied Natural Gas (LNG) that is considered a clean fuel compared to the conventional liquid fossil fuels, has been attracting the interest of the maritime industry as its use leads to the reduction of the greenhouse and nongreenhouse gaseous emissions [1]. With the fuel sulphur global limit of $0.5 \%$ (on mass basis) coming into effect on 1st January 2020 [2], the LNG fuel seems to be a viable solution for vessels sailing both inside and outside Sulphur Emission Control Areas (SECAs). At the same time the continuous rapid expansion of the global LNG infrastructure along with the lower LNG fuel price levels, is advantageous and renders LNG as an attractive green fuel alternative [3]. To address this and considering that marine two-stroke engines are the most commonly used solution for large merchant ships [4,5], the marine engine manufacturers have developed dual fuel (DF) versions of their engines which can operate either in diesel or dual fuel mode.

Two different pathways have been followed by the major two-stroke engine manufacturers. These include: a) the high-pressure direct injection of natural gas within the engine cylinders leading to the diffusive gas fuel combustion concept [6] and, b) the low-pressure injection of the natural gas during the compression process resulting in a premixed combustion process $[7,8]$. Compared to each other, the former requires the use of exhaust gas after-treatment systems in order to fully comply with the environmental regulations for NOx emissions, whilst the low-pressure lean burn technology is sensitive to problems such as knocking and methane slip [9]. In both cases, the computational investigation of the engine operation in both modes is expected to provide insights for the engine characteristics, performance and emissions as well as the turbocharger (TC) matching, which has to accommodate the two different modes of operation.

Various modelling approaches have been extensively used for analysing the marine engines and ship propulsion systems. Generally, and depending on the type of application, the most common ones include: 
the cycle mean value engine models (MVEM), the zero- or one-dimensional models (0D/1D) and the three-dimensional models (3D). Each of these approaches vary in terms of complexity, computational time, expected accuracy, input data requirements and capabilities. Previous investigations using MVEMs for marine engines are reported in [10-12]. Various versions of combined zero/one-dimensional, and mean value/zero- dimensional engine models have been extensively used to investigate the performance and emission characteristics of marine engines as reported in [13-18]. Such approaches are usually preferred due to their trade-off between the needed model complexity, required input and computational time. The one-dimensional models are mainly used to represent the flow inside intake and exhaust pipes, pipe junctions and manifolds [19, 20]. Three-dimensional (3D) computational fluid dynamics (CFD) modelling is also a more detailed method for simulating the engine operation typically used for the engine components design as it focuses in greater detail on the in-cylinder processes, where other approaches have limited applications. Examples of pertinent investigations that have developed 3D CFD models to examine the effects of combustion on the engine performance and its emissions are reported in $[21-23]$.

With regard to the development of mathematical models for marine diesel engines, Theotokatos [11] reported the development of an in-house MVEM in the MATLAB/Simulink environment and its usage for studying the operation of a large marine two-stroke diesel engine. For the prediction of the steadystate performance and transient response of various engine configurations including four-stroke, twostroke, Diesel, natural gas, turbocompound engines, etc., a detailed zero-dimensional code has been developed and used for a number of years in [24, 25]. Scappin et al. [14] developed a zero-dimensional model of a marine two-stroke low speed diesel engine to predict its performance and NOx emissions. Savva and Hountalas [26] developed a pseudo-multi-zone model applied on large-scale two and fourstroke diesel engines for the prediction of NOx emissions at various operating conditions. Guan et al. [27] have developed a two-stroke engine model using a modular zero-dimensional simulation tool. Raptotasios et al. [28] applied a phenomenological multi-zone combustion model on a marine two-stroke diesel engine with the aim of predicting the exhaust gas recirculation (EGR) effect on NOx emissions and engine performance and investigating the in-cylinder combustion and NOx formation mechanisms. Wang et al. [29], developed a 0D/1D model of a marine two-stroke diesel engine in the GT-Power 
software and examined the effect of exhaust gas recirculation (EGR) combined with cylinder bypass (CB) and exhaust gas bypass (EGB) on NOx emissions. Cordtz et al. [30], developed a zero-dimensional multizone combustion model, based on experimental pressure traces, of a large low speed two-stroke diesel engine, to investigate the in-cylinder formation of gaseous sulphur trioxide $\left(\mathrm{SO}_{3}\right)$ by means of a detailed reaction mechanism. The same model was used by Cordtz et al. [31] to simulate the in-cylinder condensation of sulphuric acid and water vapour. Feng et al. [32], investigated the effect of EGR combined with Miller-cycle methods on NOx emissions by developing a combined 1D / 3D model of a two-stroke marine diesel engine, using the AVL Boost and AVL FIRE simulation tools. In this investigation the output of the one-dimensional model was used to determine the initial conditions for the 3D CFD calculations. Moreover, Wei et al. [33], investigated the influence of the swirl flow and oxygen concentration on spray, combustion and emissions of a two-stroke marine diesel engine running on HFO, by developing a 3D combustion and spray model in the CONVERGE CFD software. In addition, Sun et al. [34] examined the effects of inlet pressure, EGR and start of injection (SOI) timing on NOx emissions, by developing a three-dimensional model of a marine two-stroke diesel engine in the CONVERGE CFD software. Chryssakis et al. [21] developed a two-stroke diesel engine 3D model using the KIVA-3V code to examine the effects of two water injection strategies on the NOx emissions. Pang et al. [35], performed three-dimensional computational fluid dynamics (CFD) studies of sulphur oxides and $\mathrm{H}_{2} \mathrm{SO}_{4}$ formation processes in a large marine two-stroke diesel engine by using the STAR-CCM+ commercial code. Kyriakides et al. [36], developed a two-stroke diesel engine 3D model using the KIVA-3V code to investigate the effect of fuel properties on spray atomization by performing simulations in a constantvolume high-pressure chamber. Goldsworthy [37] investigated the vaporization and combustion of heavy residual based fuel oil in high-pressure sprays, in the context of marine diesel engines by developing a simplified 3D CFD model using the StarCD code.

From the preceding analysis, it can be deduced that the marine two-stroke and four-stroke diesel engines have been investigated in a great extent. However, very few studies have been published focusing on the modelling/simulation of marine DF engines, which differ from the conventional diesel engine models in terms of combustion and knocking characteristics. Examples of pertinent investigations dealing with the experimental and numerical analysis and settings optimisation for marine DF four-stroke engines as well 
as their control during fuel transitions have been reported in [38-41]. Furthermore, Theotokatos et al. [42] developed a 0D/1D four-stroke engine model in the GT-Power software, to evaluate the performance and emission characteristics of a large marine four-stroke engine. Ritzke [43] developed a combined 0D/1D and 3D CFD model to simulate the operation of a four-stroke dual fuel marine engine in the AVL Boost and FIRE simulation tools. The $0 \mathrm{D} / 1 \mathrm{D}$ engine model was used to generate information regarding the initial and boundary conditions, and subsequently these conditions were used for the 3D CFD model. Sixel et al. [44] developed a 0D/1D model for a four-stroke gas-diesel engine using the GT-Power software in order to predict its performance characteristics and calibrated the combustion sub-models based on an experimental investigation for two DF single cylinder engines of different size. The developed model was considered capable of being used in the development of dual fuel or gas-diesel engines at a preliminary stage. Moriyoshi et al. [45] performed a 3D CFD simulation of the combustion process of a four-stroke natural gas engine in order to analyse the combustion process and increase the thermal efficiency. Yang et al. [46] examined the combustion instabilities of a four-stroke pre-mixed lean-burn dual fuel engine by following a 3D CFD modelling approach to represent the in-cylinder processes. This investigation included the analysis of the effect of gas injection timing on the combustion system complexity.

In a recent publication, Ott et al. [47] described the technology development of the premixed combustion large marine engines and provided experimental data from the engines type approval tests. Notwithstanding the above, apart from a preliminary study of the authors [48], studies for marine twostroke DF engines have not been reported in the available literature, possibly due to the recent development of such engines and the unavailability of data. Hence, such studies are quite valuable for obtaining a better understanding of the engine operation as well as the involved processes of these engines. In this respect, to the best of authors' knowledge, this is the first comprehensive study focusing on the modelling and parametric investigation of a large two-stroke marine DF engine operating on the low-pressure lean burn technology, which is currently one of the two industry available technologies not only for LNG carriers but for ocean-going LNG-fuelled vessels [49]. The engine model is set up in the GT-Power computational tool. Following the model validation, the engine operation in both modes and at various loads is investigated and the results are analysed and discussed for comparing the engine 
performance and emissions as well as the turbocharger matching in the both engine modes. Furthermore, a parametric investigation is carried out with the aim of optimising the engine settings in the DF mode in order to further reduce the $\mathrm{NOx}$ and $\mathrm{CO}_{2}$ emissions and improve the engine efficiency, which reveals the trade-offs between the engine settings and the engine performance/emissions parameter.

\section{ENGINE MODELLING}

\subsection{Investigated Engine}

In this study, the 5RT-flex50DF engine, from Winterthur Gas \& Diesel [50] was investigated. This engine has been designed for large merchant vessels such as LNG carriers, handysize tankers and bulk carriers, as well as feeder container vessels. It is a camshaftless low-speed, two-stroke DF engine consisting of five cylinders connected in an in-line arrangement, one turbocharger unit, one air cooler unit and two auxiliary blowers. It employs a common rail diesel fuel injection system and gas injection at low pressure during the compression phase of each cylinder. The engine can operate in the diesel mode by using heavy fuel oil or marine diesel/gas oil. In the DF mode, natural gas is used as the main fuel while diesel fuel is utilized as pilot fuel in order to commence the combustion ignition. When running in the DF mode, the engine is fully compliant with the International Maritime Organisation (IMO) Tier III NOx emission limits [51] without requiring the use of exhaust gas after-treatment systems. The main engine characteristics are reported in Table 1.

Table 1 Engine main characteristics

\begin{tabular}{|l|c|}
\hline MCR power (kW) & 7200 \\
\hline MCR speed (rpm) & 124 \\
\hline BMEP at MCR (bar) & 17.3 \\
\hline BSFC at MCR - Diesel mode $(\mathrm{g} / \mathrm{kWh})$ & 182.1 \\
\hline BSEC at MCR - DF mode $(\mathrm{kJ} / \mathrm{kWh})$ & 7122 \\
\hline Bore $(\mathrm{mm})$ & 500 \\
\hline Stroke $(\mathrm{mm})$ & 2050 \\
\hline No. of cylinders (-) & 5 \\
\hline Auxiliary Blowers (-) & 2 \\
\hline Turbocharger units (-) & 1 \\
\hline
\end{tabular}

MCR: maximum continuous rating; BMEP: brake mean effective pressure; BSFC: brake specific fuel consumption; BSEC: brake specific energy consumption 


\subsection{Engine Model Set-up and Calibration}

The GT-Power software [52], which is a renowned 0D/1D simulation program for engine modelling and analysis, was employed for the engine simulation. To set up the engine model, various components and reference objects were selected from the software library and interconnected by using available connectors, so that the engine layout is represented in an adequate level.

The modelling process was initiated by setting up and validating one single cylinder block in diesel mode and subsequently modifying it to cover the dual fuel mode by adding an additional gas injector and pilot fuel injector. The model was then extended to cover the entire engine layout as presented in Fig. 1. As depicted in Fig. 1, the developed engine model includes blocks for the cylinders, scavenging receiver, scavenging ports (SP), exhaust valves (EV), exhaust ports (EP), exhaust receiver, turbocharger (TC), waste gate (WG), air cooler (AC), auxiliary blower, exhaust pipes (EP) and receivers. Injector elements for the liquid (FI) and gas fuels (GI) as well as for the pilot fuel (PI) are connected to each engine cylinder block.

To develop and calibrate the model for adequately predicting the engine performance and emission characteristics, various sets of input data were acquired and used. Collecting, deriving or evaluating such data is vital for the successful model setting-up. The main sources used to derive the required input data were: the engine operation manual [50], two separate 3D models of the intake and exhaust system, a similar zero-dimensional engine model built in the MATLAB/Simulink environment [27] and data provided directly by the manufacturer. In specific, the data required for the modelling process included the engine geometry, the scavenging ports and exhaust valve profiles, the fuels injection timing, the heat release rate for each engine load, the compressor and turbine performance maps, the air cooler characteristics, the auxiliary blower characteristics and the waste gate valve geometry, measured parameters from the engine trials as well as the engine manufacturer performance data available in [53]. Appropriate sub-models for representing the entire engine operating envelope were selected and calibrated. For modelling the engine cylinders processes, combustion, heat transfer, scavenging, friction, NOx emissions and knocking sub-models were appropriately identified and used.

The modified version of the Woschni heat transfer model [52], which closely imitates the classic Woschni correlation [54], calibrated for two-stroke engines, was selected and used to calculate the in- 
cylinder gas to wall heat transfer coefficient. The main difference between the classic and the modified Woschni correlation lies in the treatment of the heat transfer coefficients during the exhaust valve overlap period, where the cylinder exhaust valves are open and the heat transfer is increased by the inflow velocities through the scavenging ports [52]. Furthermore, the Chen-Flynn engine friction model [55-57] was used and its constants were calibrated based on the experimental data for the engine mechanical efficiency.

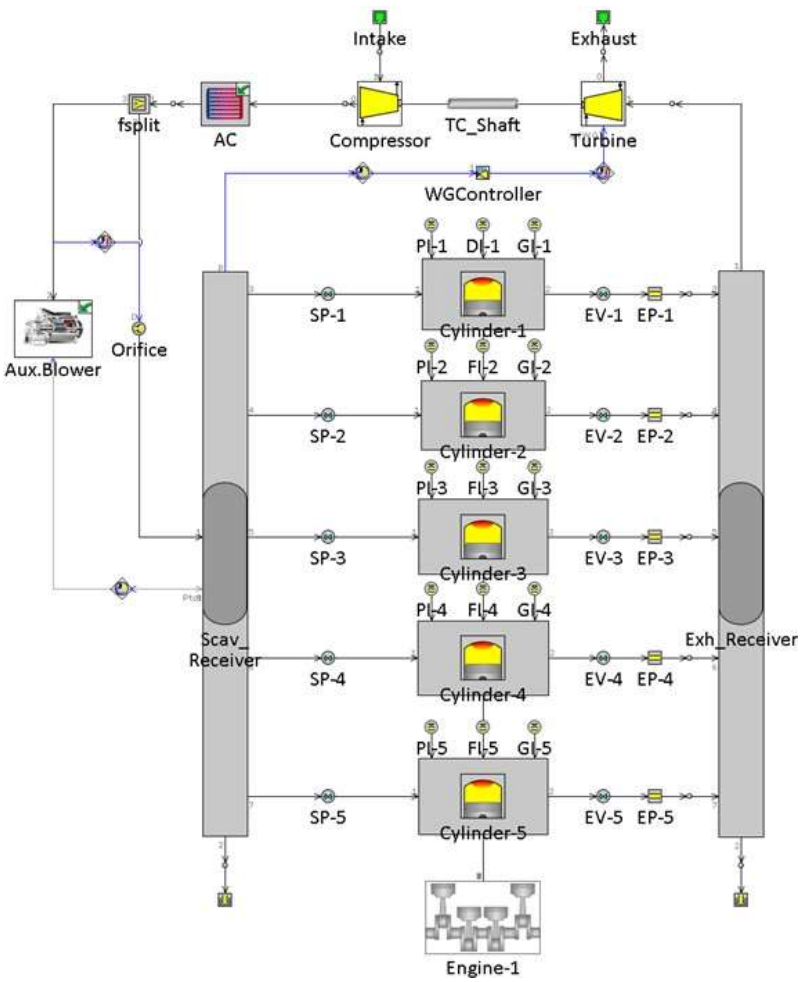

Fig. 1 Engine model layout

The combustion processes in the diesel and DF modes were modelled by using single and triple Wiebe functions, respectively. The three parts of the considered triple Wiebe function correspond to the premixed combustion of approximately half of the pilot fuel, the diffusive combustion of the remaining pilot fuel and the rapid burning of the gaseous fuel as well as the tail combustion of the cylinder residuals respectively, as reported in [58]. In this respect, the fuel burning rate for the DF mode is calculated according to the following equation [52]:

$$
x_{b}(\theta)=\sum_{i=1}^{3}\left[\left(\frac{F F_{i}}{\sum_{i=1}^{3} F F_{i}}\right) x_{b, i}(\theta)\right]
$$


211 The combustion model parameters were calibrated for $25 \%, 50 \%, 75 \%$ and $100 \%$ loads to match the 212 heat release rates as provided by the engine manufacturer. The resultant heat release curves used to 213 simulate combustion in the diesel and DF modes for $75 \%$ engine load are illustrated in Fig. 2.

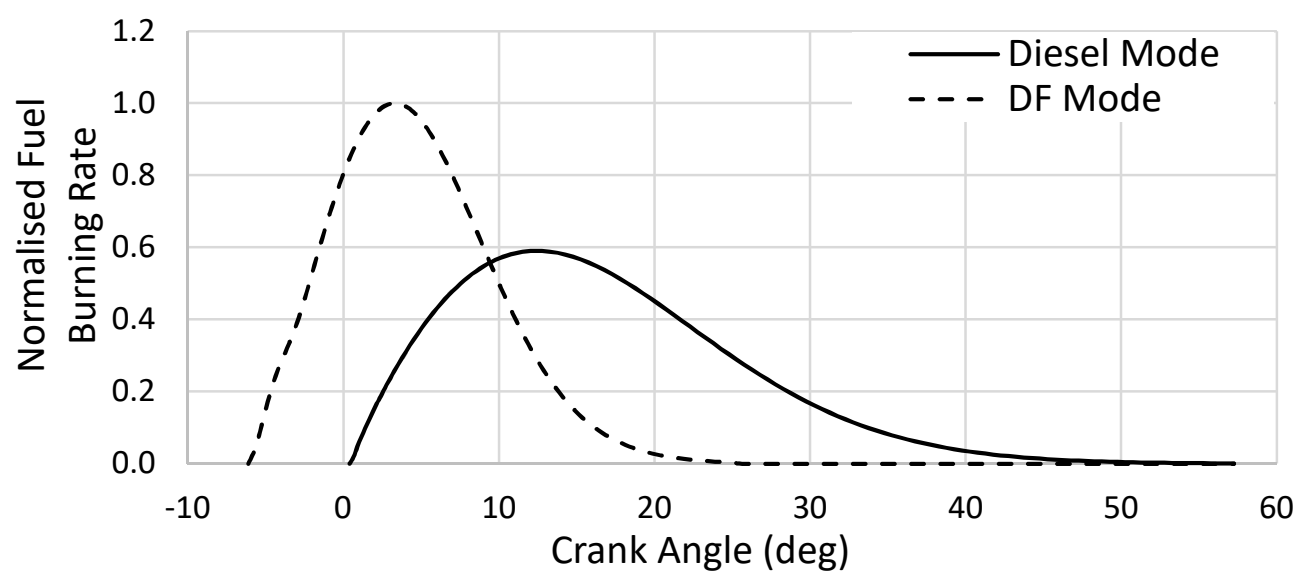

Fig. 2 Normalised fuel burning rates in diesel and DF modes at 75\% engine load

The amount of each fuel (diesel and natural gas) injected per cycle was calculated by considering each fuel specific energy consumption and lower heating value, respectively. The injection delay was estimated for the diesel mode according to the Sitkei equation as described in [59], whereas the ignition delay for the DF mode was approximated by using the equations and data reported in $[44,60]$.

The scavenging process was modelled in GT-Power by using a two-zone model [52, 61], the setting up of which requires as input the relationship between the in-cylinder gas residual ratio and the residual ratio of the exhaust gas exiting the cylinder. The former is the ratio of the burned gas mass in the cylinder to the total mass in the cylinder, whereas the latter corresponds to the ratio of the burned gas mass exiting the cylinder to the total mass exiting the cylinder. As no data was available for approximating this relationship, an existing in-house simulation tool developed in the MATLAB/Simulink environment, was used for simulating the operation of one-cylinder block in the diesel mode and thus estimating the required scavenging process parameters [27]. Both models consider two zones (one of pure air and one containing exhaust gas) within the engine cylinder during the scavenging process. For qualitatively validating the scavenging model, the calculated scavenging efficiency versus delivery ratio plot was compared to results derived by using CFD analysis for a similar engine $[62,63]$, for an operating point with a similar scavenging pressures. The model results were comparable with the CFD 
results reported in [63], which indicates that the model is adequate for representing the scavenging process.

A two-zone model was also used to represent the cylinder closed cycle. According to this, the combustion chamber is subdivided into two zones; the unburned zone which contains unburned mixture (i.e. air and fuel) and the burned zone which contains burned mixture. Both zones states are described in terms of pressure, temperature, volume, air-fuel ratio and species concentration. These parameters are calculated by solving at each time step (in each zone) the energy conservation equation, the continuity equation and the ideal gas equation considering the chemical kinetics, the working media properties and the cylinder volume along with its change.

To predict the nitrogen oxides (NOx) emissions, the extended Zeldovich mechanism [52] was used and calibrated at $75 \%$ load, according to which the nitrogen monoxide (NO) concentration is calculated by using the following equation:

$$
\frac{d[N O]}{d t}=4.710^{13}\left[N_{2}\right]\left[O_{2}\right]^{1 / 2} \exp \left(-\frac{67,837}{T}\right)
$$

The NO concentration is assumed to approximate the NOx concentration as the former is considered the predominant nitrogen oxide produced inside the engine cylinder. As the thermal NOx formation takes place in the burned zone, the burned zone temperature was used as input in the NOx model.

For evaluating the engine combustion stability, the Worret knocking criterion [64] was considered, according to which the probability of the engine cylinders knocking is calculated. In this model, the probability of knocking is estimated by means of an induction time integral $\left(\mathrm{I}_{\mathrm{K}}\right)$ and a constant parameter K, which are calculated according to the following equations, as reported in [59]:

$$
I_{K}=\left(\frac{1}{6 n} \frac{1}{c 10^{-3}} \int_{\theta_{C S}}^{\theta_{K}} p^{a} e^{\left(\frac{b}{T}\right)} d \theta\right)\left(\frac{\theta_{75 m f b}+6}{\theta_{75 m f b_{r e f}}+6}\right)^{a_{I K}}
$$

$$
K=k_{r e f}\left(\frac{\theta_{50 m f b}+8}{\theta_{50 m f b_{r e f}}+8}\right)^{a_{k}}\left(\frac{b_{k}-c_{k} \lambda}{b_{k}-c_{k} \lambda_{r e f}}\right)
$$


The former takes into consideration the pressure-temperature history in the combustion chamber, whereas the latter represents a quotient of the combustion progress between the start of knocking and the entire combustion duration whilst it accounts for the combustion chamber space, which depends on different quantities (e.g. change motion level, combustion chamber space etc.). To obtain $\mathrm{I}_{\mathrm{K}}$ and $\mathrm{K}$, the following parameters need to be considered: a) a set of reference parameters including the crank angles at $75 \%$ and $50 \%$ of the burned fuel mass fraction, the air-fuel ratio and a reference $\mathrm{K}$-value (that are calculated for a known cycle in the knocking boundary), b) the model constants that depend on the selected combustion model and, c) the unburned zone temperature. Then, the knocking sub-model calculates at each operating point, the crank angle $\left(\theta_{E}\right)$, based on the calculated K-value, as well as the crank angle $\left(\theta_{K}\right)$ at which $\mathrm{I}_{\mathrm{K}}$ becomes equal to one. The former is calculated according to the following equation:

$$
\theta_{E}=\theta_{S O C}+K \Delta \theta_{C D}
$$

Knocking occurs when the following inequality holds: $\theta_{K}<\theta_{E}$. However, $\mathrm{I}_{\mathrm{K}}$ and $\mathrm{K}$ have a dispersion range of $15 \%$ and $5 \%$, respectively. In this respect, the knocking probability is calculated according to the following equation:

$$
P(k)=100\left(a_{k p}+b_{k p} \ln \left(\frac{\Delta \theta_{K D R, \max }}{2}\right)\right)^{\Delta \theta_{K D R}}
$$

where $\Delta \theta_{K D R}$ is the crank angle range, resulting from the superimposition of the $\mathrm{I}_{\mathrm{K}}$ and $\mathrm{K}$ dispersion ranges.

Considering the above, to calibrate the model parameters, an engine operating point in the knocking boundary needs to be modelled. As the operating window is always narrower at high engine loads [47, 65], proper calibration of the knocking model parameters at this load region would ensure that no abnormal combustion would occur at lower loads. Hence in the present study, the $100 \%$ engine load was used as a reference point for the calibration of the knocking model by considering a pilot injection timing, which would lead to an operating point lying on the knocking boundary.

The validation of the knocking model predictive capabilities was performed for all the investigated engine loads in the DF mode and was based on the fact that the examined engine does not face knocking problems at any operating condition, as indicated by the engine manufacturer [50]. Subsequently, the 
calibrated model was used to characterise combustion by using the calculated knocking probability for the investigated operating points during the parametric investigation process, where various combinations of engine settings could increase the probability of knocking.

In the DF mode, the exhaust gas waste gate opening is controlled by using a proportional-integral (PI) controller to adjust the combustion air to fuel equivalence ratio by regulating the scavenge air receiver pressure. By this means, combustion instabilities including knocking and misfiring are prevented. In addition, turbocharger overspeed at high engine loads in diesel mode can be avoided.

To setup the air cooler model, a configuration of pipes and Y-junctions was used according to a onedimensional compressible fluid dynamics consideration to represent the flow and heat transfer in the flow components of the engine system. In this respect, the desired outlet temperature of the air cooler was estimated by adjusting the heat transfer rate of the pipe objects. The pressure drop across the air cooler was simulated based on data from similar DF engines.

Finally, to simulate the engine operation at loads below $40 \%$, an auxiliary blower model had to be set up and calibrated by providing as input the blower characteristic curve (pressure increase vs flow rate). At such loads, the air required for the operation of the engine is solely provided through the auxiliary blower, whilst when the auxiliary blowers are deactivated the scavenge air receiver flaps are shut-off to prevent the air back-flow. Hence, a deterministic logic controller that employs conditional programming into the model was developed and used to activate or deactivate the auxiliary blower and isolate or free the auxiliary blower air path.

\section{Results and Discussion}

\subsection{Engine operation investigation}

The engine operation under steady state conditions was examined by performing simulation runs in a load range from $25 \%$ to $100 \%$ of the maximum continuous rating (MCR) point. Preliminary calibration of the model constants was performed for a reference point ( $75 \%$ engine load) and simulation runs were conducted. Subsequently, the fine tuning of the model constants was performed at the reference point for obtaining results of adequate accuracy. Next, simulation runs at the other operating point were performed by considering the previously calibrated models constants and recalibrating the 
combustion model. The derived percentage errors between the measured and predicted parameters are reported in Table 2.

Table 2 Predictions percentage error

\begin{tabular}{|l|c|c|c|c|}
\hline \multirow{2}{*}{ Engine Load (\%MCR) } & $\mathbf{1 0 0}$ & $\mathbf{7 5}$ & $\mathbf{5 0}$ & $\mathbf{2 5}$ \\
\cline { 2 - 5 } & \multicolumn{4}{|c|}{ Diesel mode- Error (\%) } \\
\hline Brake Power & -3.6 & -2.6 & -1.5 & -1.5 \\
\hline Cylinder Maximum Pressure & -0.7 & -1.5 & -0.9 & -0.6 \\
\hline Cylinder Compression Pressure & -3.2 & -1.6 & 1.7 & 3.0 \\
\hline Scavenging Receiver Pressure & 0.2 & 1.3 & 2.4 & 0.6 \\
\hline Exhaust Receiver Temperature & 3.6 & 3.2 & 2.4 & 2.6 \\
\hline NOx emissions & 1.4 & 0.06 & 0.8 & 1.4 \\
\hline & \multicolumn{3}{|c|}{ Dual fuel mode- Error (\%) } \\
\hline Brake Power & -2.0 & -1.7 & -2.3 & -2.3 \\
\hline Cylinder Maximum Pressure & 1.0 & 0.3 & 1.5 & 0.4 \\
\hline Cylinder Compression Pressure & -1.8 & -0.4 & 1.4 & 1.1 \\
\hline Scavenging Receiver Pressure & 0.9 & 0.9 & 0.7 & 0.4 \\
\hline Exhaust Receiver Temperature & 2.1 & 1.8 & 0.8 & 2.2 \\
\hline NOx emissions & 0.3 & -0.9 & 0.8 & -1.5 \\
\hline
\end{tabular}

From Table 2, it can be inferred that the simulation results are of acceptable accuracy as the obtained maximum error was around $\pm 3.6 \%$. The maximum deviation of the simulation results from the measured data provided by the engine manufacturer was found at the exhaust gas temperature. However, this parameter is challenging to be accurately measured in practice and thus such a deviation was expected; even though it is still within the acceptable levels of adequate accuracy. Therefore, the developed model can be considered a reliable tool for representing the engine steady state behaviour and as a result, it can be used with fidelity for the subsequent engine parametric investigation.

A set of the derived simulation results including the engine performance parameters, the compressor and turbine efficiencies, the $\mathrm{NOx}$ and $\mathrm{CO}_{2}$ emissions, the cylinder pressure and temperature diagrams as well as the compressor operating points superimposed on the compressor map is shown in Fig. 3. In this figure, the manufacturer data derived by using the General Technical Data (GTD) program [53] are also presented. The comparison of the simulation results and the engine manufacturer data also verifies the preceding observation with regard to the simulation results adequate accuracy.

The engine power output and the brake mean effective pressure (BMEP) were found to be similar in both diesel and DF modes. In the DF mode, the indicated mean effective pressure (IMEP) increases 
slightly due to the obtained higher in-cylinder pressures caused by the advanced start of injection (and 330 consequently the earlier start of combustion as it can also be inferred from the cylinder pressure and 331 temperature diagrams). This setting for the pilot fuel injection was used in order to avoid knocking. As 332 a consequence, the friction mean effective pressure slightly increases, as it depends on the maximum 333 cylinder pressure. 

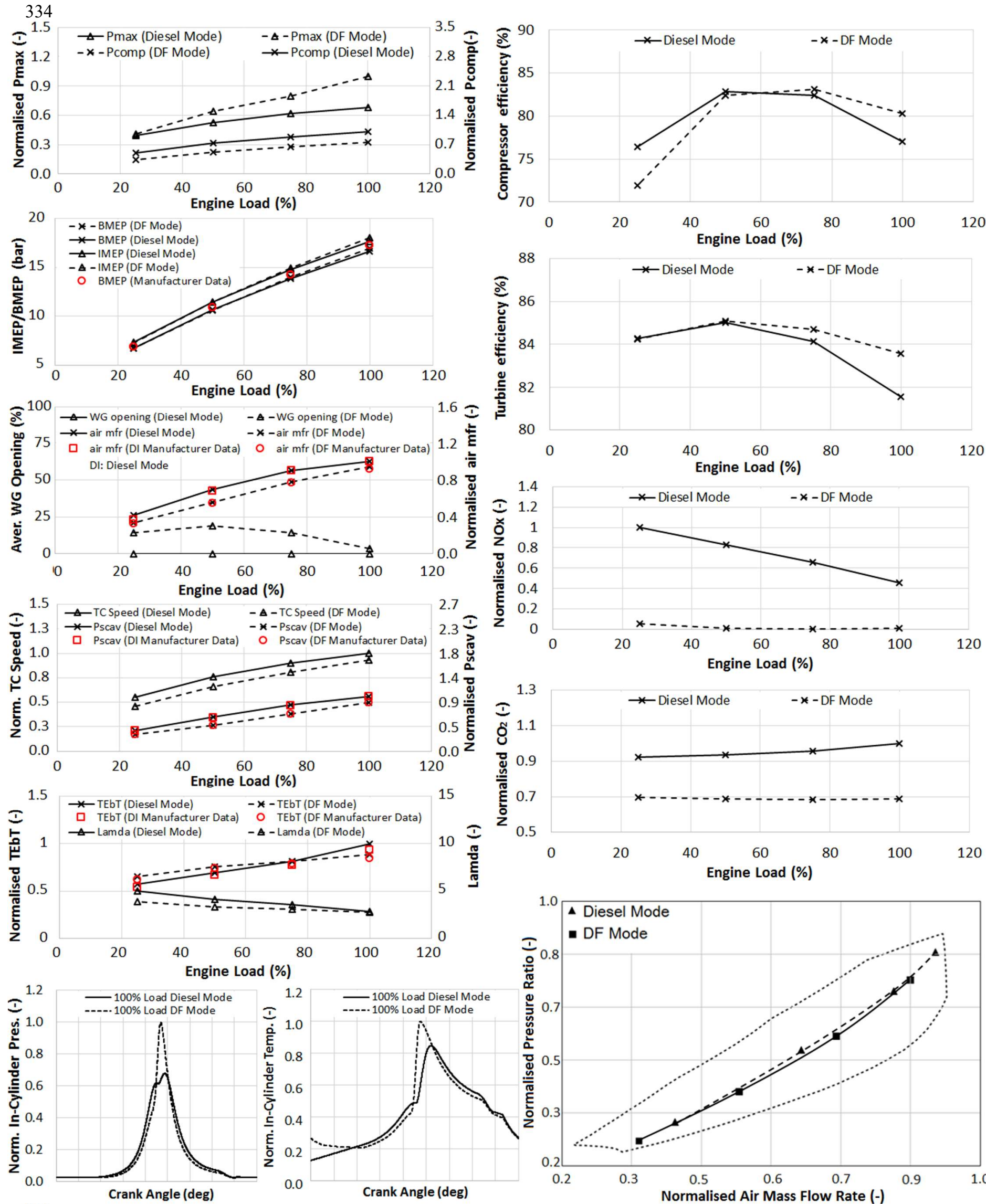

Fig. 3 Simulation results (steady state conditions) 
Furthermore, both the turbocharger shaft speed and as a result, the scavenge air receiver pressure are greater when the engine operates in the diesel mode, hence, the in-cylinder pressure during the compression process in the DF mode is reduced compared to the diesel mode operation. This is owing to the opening of the waste gate bypass valve, which is employed for controlling the combustion air-tofuel ratio in the DF mode. However, the firing (maximum) pressure in the diesel mode is much lower (compared to maximum pressure obtained in the DF mode) as a result of the retarded start of combustion and the longer combustion duration. This results in a slightly lower indicated power in diesel mode which along with the lower friction leads to an almost retained brake power in both modes of operation. It must be noted that the respective diesel version of the investigated engine reaches a cylinder maximum pressure similar to the one attained in the DF mode. In order for the investigated engine to accommodate the combustion of the gas fuel (in the DF mode), the engine was derated to avoid knocking issues (by using a lower compression ratio and by the opening of the exhaust gas waste gate valve). In addition, in order for the engine to comply with the Tier II NOx emissions limit when operating in the diesel mode, the start of injection is retarded resulting in a much lower cylinder maximum pressure as shown in Fig. 3 (compared to the maximum pressure of both the DF mode and a diesel engine of similar size). This implies that it is the DF mode which primarily defines the required engine settings to render the stable engine operation, whilst the diesel mode engine settings are adjusted to allow the compliance with the engine NOx emissions limits.

From Fig. 3, it can be observed that the exhaust gas receiver temperature in the DF mode is greater (than the respective parameter in the diesel mode) for loads up to $75 \%$, whereas it is less for loads above $75 \%$. This is attributed to the fact that the exhaust gas receiver temperature is affected by the in-cylinder temperature at the exhaust valve opening (which depends on the combustion heat release rate and airfuel ratio) and the exhaust gas mass flow rate (which depends on the turbocharger speed and waste gate opening). In the DF mode, the waste gate opening increases as the engine load reduces to match the targeted scavenge air receiver pressure, and as a result the air flow rate takes lower values than the ones in the diesel mode.

From the preceding, it can be inferred that the turbocharger performance characteristics will differ as the turbocharger speed, pressure ratio and flow rate are considerably reduced in the DF mode throughout 
the entire operating region due to the waste gate valve opening. In this respect, it can be observed that both the turbine and the compressor efficiencies vary depending on the operating mode. For engine loads in the range from $50 \%$ to $75 \%$ in both modes of operation, both the compressor and turbine efficiencies are high enough but with slight variations as indicated in Fig. 3. Additionally, in the engine loads range from $75 \%$ to $100 \%$, both the compressor and turbine efficiencies reduce in both modes of operation. Attention has to be taken at the lowest and highest engine load regions. This is due to the fact that in low engine loads (below 40\%), the turbocharger becomes unable to provide the engine cylinders with the required amount of air for combustion due to the limited available exhaust gas energy. Thus, the auxiliary blower is activated to provide the required air flow rate.

In the diesel mode, the operating point of the compressor is closer to the surge line when the engine operates at high engine loads (close to 100\%) and the turbocharger speed is very close to its maximum value. However, the waste gate opening can prevent a potential turbocharger overspeed. Despite the differences in the turbocharger operation at the two engine operating modes, it can be concluded that the selected turbocharger unit effectively matches the engine as it provides sufficient air quantities with high efficiencies at all loads in both engine operating modes and additionally provides sufficient surge margin. Noticeable is also that all the operating points lie on a single operating line, which is as expected for two-stroke engines [66].

The NOx emissions strongly depend on the in-cylinder temperature, pressure and trapped oxygen $\left(\mathrm{O}_{2}\right)$ concentration, which are affected by the engine settings and the trapped air-fuel ratio. The maximum in-cylinder temperature and pressure values are greater in the DF mode; however due to the shorter combustion duration, the in-cylinder temperature and pressure reduce more rapidly compared to the diesel mode. This along with the DF lean premixed combustion implies that the NOx formation rate will be effectively less in the DF mode, compared to the diesel mode as also indicated from the results of Fig. 3. In addition, higher values of the specific NOx emissions are obtained as the load reduces, which is also reported in $[67,68]$. In fact, the NOx emissions for the diesel mode comply with Tier II limits, whereas the Tier III limit requirements are satisfied by the DF [47].

The $\mathrm{CO}_{2}$ emissions in the DF mode are also reduced by $28 \%$ in average compared to the diesel mode. This is due to the lower carbon to hydrogen ratio of the natural gas compared to the respective one of 
the diesel fuel. Noticeable is also the greater reduction of $\mathrm{CO}_{2}$ emissions at high loads where the efficiency difference between the DF and diesel mode is greater. In summary, it can be concluded that the NOx and $\mathrm{CO}_{2}$ emissions significantly reduce when the engine operates in DF mode as expected from the results reported in the literature.

\subsection{Parametric runs}

Having simulated the performance and emission characteristics of the investigated engine in steady state conditions, a parametric study for optimising the engine settings in the DF mode was performed with the aim of simultaneously reducing the $\mathrm{NOx}$ and $\mathrm{CO}_{2}$ emissions. The latter are proportional to the engine brake specific energy consumption (BSEC) and inversely proportional to the engine brake efficiency.

The parametric investigation was initiated by conducting a sensitivity study. In this respect, multiple simulation runs were performed, each time by manually altering a predetermined parameter of the engine model in order to identify the parameters which significantly affect the $\mathrm{NOx}$ and $\mathrm{CO}_{2}$ emissions. The following engine settings changes (from their respective reference values) were considered for each operating point: pilot fuel injection timing $(-3,0$ and +3 degrees crank angle (CA)), exhaust valve profile shift $(-5,0$ and +5 degrees $\mathrm{CA})$, scavenging air receiver pressure $(-5 \%, 0 \%$ and $+5 \%)$ and compression ratio $(-5 \%, 0 \%$ and $+5 \%)$. In total, 81 different parametric runs at each engine operating point were conducted.

However, some slight modifications had to be made to the developed model in order to run the parametric simulation cases. This is owing to the fact that the varying pilot fuel injection timing setting affects the combustion process. Hence, it was assumed that the multi-Wiebe functions employed by the combustion model would only be shifted according to the injection timing taking into account an appropriate ignition delay calculation.

The derived results for the $75 \%$ load, which include the $\mathrm{NOx}$ and $\mathrm{CO}_{2}$ emissions trade-off, the cylinder maximum pressure as well as the cylinder pressure maximum permissible value, are depicted in Fig. 4-

5. From these figures, it can be inferred that the greatest simultaneous reduction of $\mathrm{CO}_{2}$ and $\mathrm{NOx}$ 
emissions is obtained for the reference value of the pilot fuel injection timing and therefore, it is concluded that this parameter has been optimised by the engine manufacturer.

The exhaust valve profile shifting towards later opening/closing results in a longer expansion stroke and a shorter compression period. This leads to a marginally greater engine efficiency and a rise of the in-cylinder temperature, respectively; the latter owing to the increased amount of residual exhaust gases remaining within the cylinder due to less effective scavenging (in comparison with the reference point).
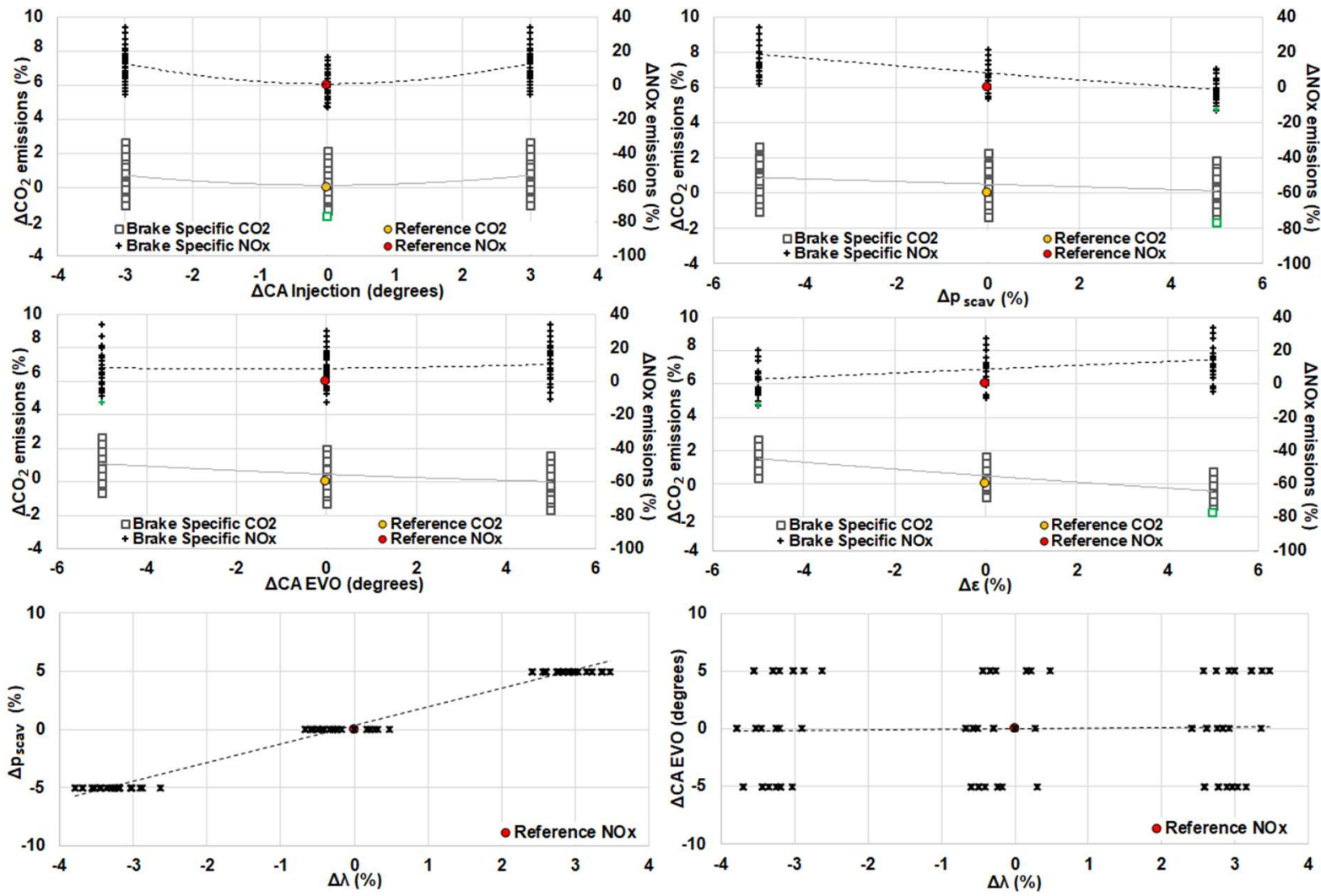

Fig. 4 Effect of model parameters on emissions

The boost pressure increase setting, which can be obtained by reducing the waste gate valve opening, results in a greater turbocharger shaft speed and scavenging receiver pressure, which in consequence, provides more trapped air in the engine cylinders (leading to a leaner combustion) and a higher maximum pressure. As a result, both the $\mathrm{NOx}$ and $\mathrm{CO}_{2}$ emissions reduce at the expense of a greater airfuel ratio and maximum pressure; the former may result in combustion instability (e.g. misfiring), 
whereas the latter can lead to greater engine cylinder components mechanical loading and wear or a cylinder pressure above its permissible value.

The compression ratio increase results in lower $\mathrm{CO}_{2}$ (i.e. higher efficiency) and greater NOx emissions. This is owing to the fact that an increase in the compression ratio leads to a reduced cylinder clearance volume. Consequently, the in-cylinder pressure increases, resulting in greater piston forces, engine torque and power as well as increased mechanical loading of the engine components. Therefore, increasing the compression ratio improves the engine efficiency and thus, reduces the $\mathrm{CO}_{2}$ emissions. However, the resultant greater in-cylinder pressures and temperatures lead to increased NOx emissions formation.

To derive the optimal engine settings, the combined effect of all the investigated model parameters had to be taken into consideration. Furthermore, the estimated knocking probability as well as the maximum permissible cylinder pressure constraints were also taken into account as both knocking and the increased cylinder pressures can jeopardise the engine integrity. The maximum in-cylinder pressure value at $100 \%$ load was assumed to be the permissible limit herein, as no information was provided with respect to the engine capability of withstanding higher pressure values. The engine may withstand higher cylinder pressures when overloaded (at 110\% MCR load); however, this scenario was not considered, mainly because it did not represent a normal operating condition at this increased load as in this case, the engine operation is usually limited to 1 hour per 12 hours of its normal operation [69].

Table 3 Potential optimum settings for $75 \%$ load

\begin{tabular}{|c|c|c|c|c|c|c|c|c|}
\hline \multicolumn{4}{|c|}{ Engine Settings } & \multicolumn{5}{|c|}{ Results } \\
\hline No. & $\Delta E V P$ & $\Delta p_{\text {scav }}$ & $\Delta \varepsilon$ & $\triangle N O x$ & $\Delta \mathrm{CO}_{2}$ & $\Delta \mathbf{P}_{\mathrm{b}}$ & $\Delta p_{\max }$ & $\mathbf{P}(\mathbf{k})$ \\
\hline & $\left({ }^{\circ} \mathrm{CA}\right)$ & (\%) & (\%) & (\%) & (\%) & (\%) & (\%) & (\%) \\
\hline 1 & 0 & 5 & 0 & -7.17 & -0.29 & 0.31 & 2.55 & 0 \\
\hline 2 & 5 & 5 & 0 & -6.79 & -0.80 & 0.81 & 0.19 & 0 \\
\hline 3 & 0 & 5 & 5 & -2.93 & -1.28 & 1.32 & 7.90 & 5 \\
\hline 4 & 5 & 5 & 5 & -1.38 & -1.69 & 1.69 & 4.95 & 0 \\
\hline
\end{tabular}




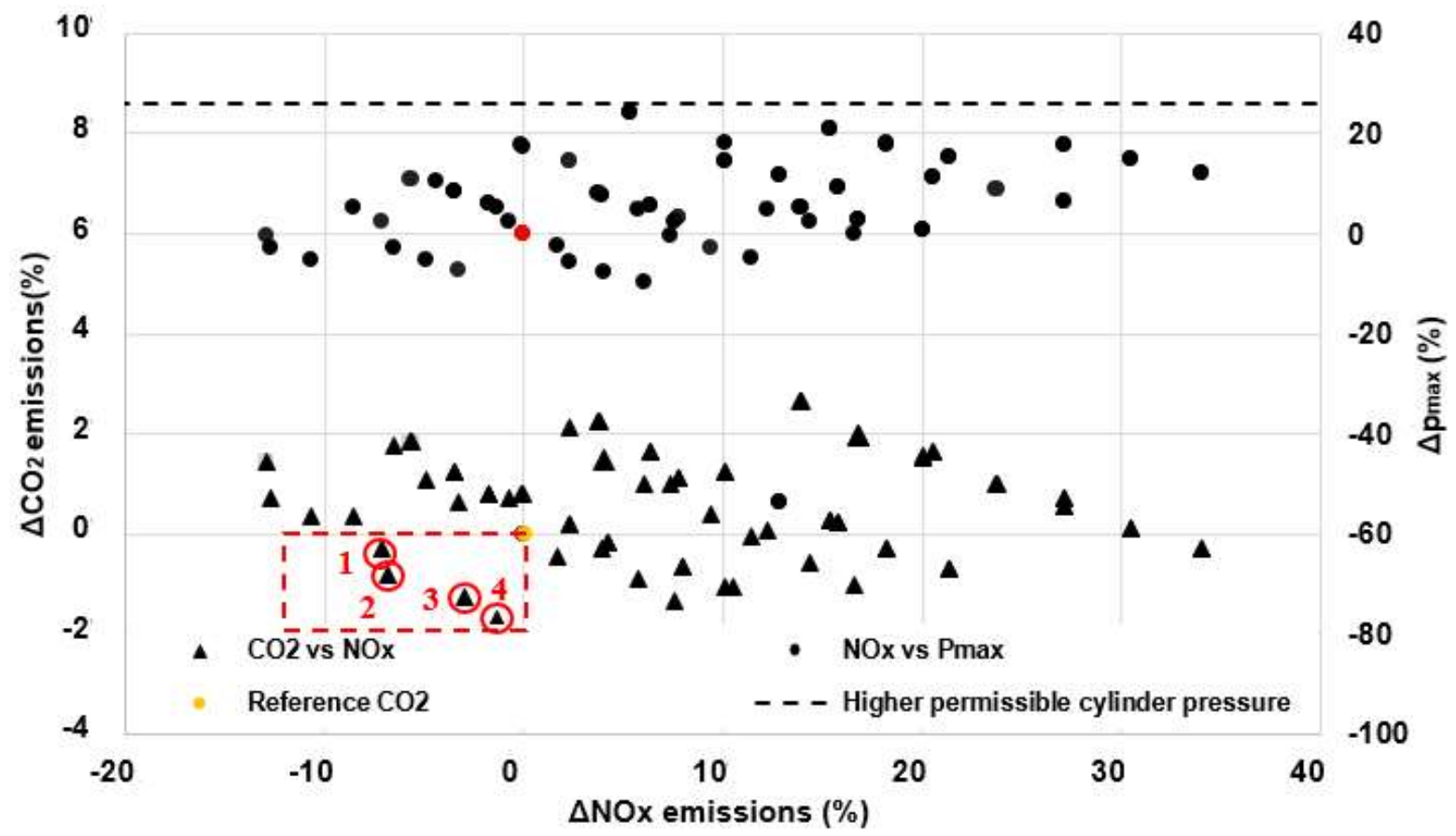

Fig.5 Parametric study results for $75 \%$ load

From the parametric runs derived results at $75 \%$ load (presented in Fig. 5), four points with a favourable trade-off between $\mathrm{CO}_{2}$ and $\mathrm{NOx}$ emissions were identified. These points settings along with the output parameters percentage changes (from their reference values) are presented in Table 3 . These results indicate that there is a combination of engine settings leading to a simultaneous reduction of the NOx and $\mathrm{CO}_{2}$ emissions. To select, however, the optimum settings, a compromise between the NOx and $\mathrm{CO}_{2}$ emissions must be made. As the current engine is fully compliant with the IMO Tier III standards when operating in DF mode, it is reasonable to assume that the final selection has to be in favour of reducing $\mathrm{CO}_{2}$ emissions and consequently improving the engine efficiency. Therefore, point No. 4 is considered to provide a set of optimised settings at $75 \%$ load leading to $1.7 \%$ reduction of $\mathrm{CO}_{2}$ emissions and $1.4 \%$ reduction of NOx emissions in comparison with the reference settings. This corresponds to shifting the exhaust valve profile by +5 degrees CA, $5 \%$ increase of the scavenge air pressure and 5\% increase of the compression ratio. Noticeable is the slight percentage increase of the output brake power which in practice does not exactly correspond to the $75 \%$ engine load case. However, the engine load can be retained at its reference value by considering an almost equivalent 
analysing the results at $50 \%$ and $25 \%$ loads (not presented herein) indicating an obtained $\mathrm{CO}_{2}$ emission reduction by $2-3 \%$ and a NOx emission reduction by $4-5 \%$.

A similar set of results for the $100 \%$ engine loads is presented in Fig. 6 . From these, it is inferred that the optimisation of the $100 \%$ load is the most challenging as the maximum pressure exceeded the permissible respective value in the majority of the investigated cases whilst the knocking probability considerably increased. Hence, an additional engine settings combination (point 5) had to be investigated. The selection of 5\% increased compression ratio for all the other investigated engine loads, rendered this setting as the targeted option also for the $100 \%$ load operating point. However, as the maximum pressure exceeded the permissible value in the majority of the investigated points, point 5 was identified as a potential option. In this point, the $\mathrm{CO}_{2}$ emissions slightly reduced whereas the NOx emissions considerably increased by around $25 \%$.

Table 4 Potential optimum settings for $100 \%$ load

\begin{tabular}{|c|c|c|c|c|c|c|c|c|}
\hline \multicolumn{4}{|c|}{ Engine Settings } & \multicolumn{5}{|c|}{ Results } \\
\hline No. & $\Delta \mathrm{EVP}$ & $\Delta p_{\text {scav }}$ & $\Delta \varepsilon$ & $\Delta$ NOx & $\Delta \mathrm{CO}_{2}$ & $\Delta \mathrm{P}_{\mathrm{b}}$ & $\Delta p_{\max }$ & $\mathbf{P}(\mathbf{k})$ \\
\hline & $\left({ }^{\circ} \mathrm{CA}\right)$ & (\%) & (\%) & (\%) & (\%) & (\%) & (\%) & (\%) \\
\hline 1 & 0 & 5 & 0 & -11.26 & -0.01 & 0.02 & 4.57 & 3 \\
\hline 2 & 5 & 5 & 0 & -4.84 & -0.07 & 0.08 & 1.21 & 0 \\
\hline 3 & 0 & 5 & 5 & -5.09 & -0.98 & 1.00 & 9.83 & 16 \\
\hline 4 & 5 & 5 & 5 & -1.05 & -0.89 & 0.92 & 8.65 & 7 \\
\hline 5 & 5 & -5 & 5 & 25.27 & -0.62 & 0.60 & -0.29 & 0 \\
\hline
\end{tabular}

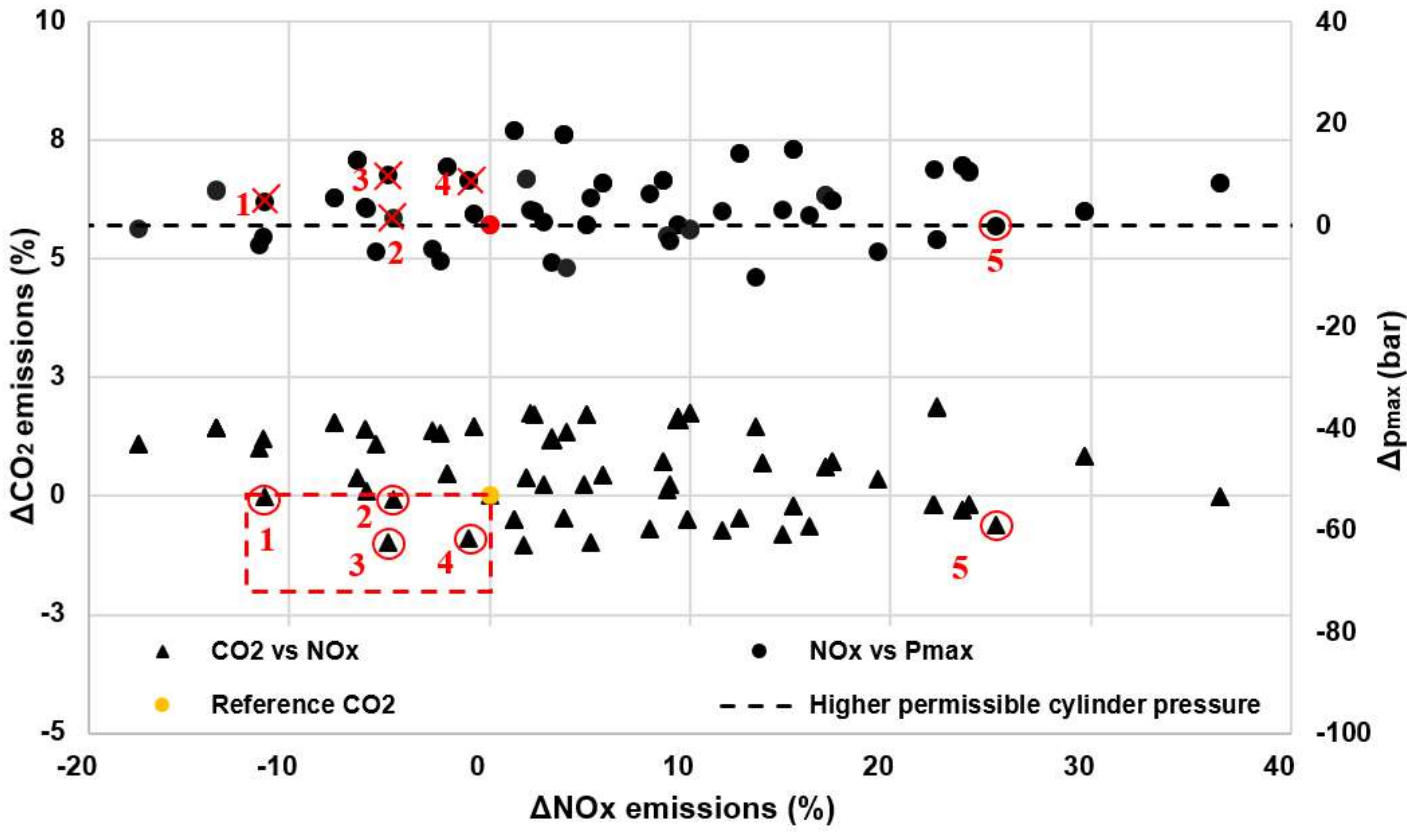

Fig.6 Parametric study results for $100 \%$ load 
Despite the significant percentage increase of the NOx emissions for point 5, the calculations performed for verifying the compatibility of the investigated engine with the IMO Tier III standards [70] revealed that the weighted NOx emissions according to E3 operating cycle [71] slightly increased by approximately $1 \%$ compared to the reference engine settings. This denotes that the engine is still compatible with the IMO Tier III standards. Notwithstanding the above, such a percentage increase may not be accepted by the market. respectively.

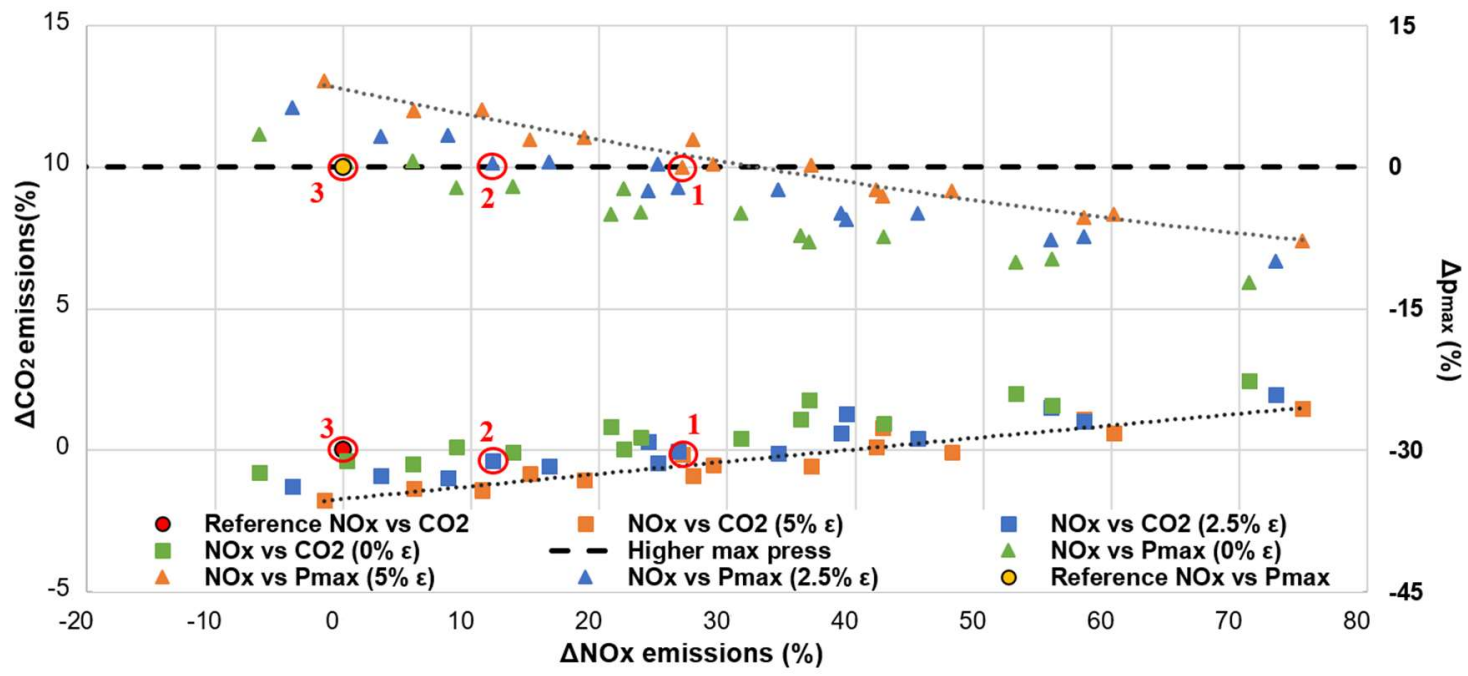


Hence, the only alternative solution in order simultaneously reduce the $\mathrm{NOx}$ and $\mathrm{CO}_{2}$ emissions at all engine loads is to set the compression ratio at its reference value. By doing so, the $\mathrm{NOx}-\mathrm{CO}_{2}$ emissions trade-off will be in favour of NOx emissions, whilst the $\mathrm{CO}_{2}$ emissions and the engine efficiency will remain approximately unchanged (as shown in Tables 3 and 4).

By considering all the preceding, it can be inferred that an increase of the compression ratio may aid the simultaneous reduction of the $\mathrm{NOx}$ and $\mathrm{CO}_{2}$ emissions at all engine loads if the engine could withstand a substantial firing pressure increase at high engine loads. Certainly, these settings cannot be applied yet due to the in-cylinder pressure limitations; however, they shall be regarded as a future option with the evolution of the engine design to operate at higher pressures, which is currently being investigated by the engine manufacturer [72]. Alternatively, the adaptation of the variable compression ratio system as the one proposed in [73] can facilitate the optimisation of the engine settings in the various loads leading to further reduction of both $\mathrm{CO}_{2}$ and $\mathrm{NOx}$ and the engine environmental footprint.

\section{CONCLUSIONS}

In the present study, a marine two-stroke DF engine was thoroughly investigated by using the GTPower software to reveal its performance and emission characteristics in both the diesel and DF modes as well as to further optimise the engine settings in terms of $\mathrm{NOx}$ and $\mathrm{CO}_{2}$ emissions trade-off by conducting parametric runs. The main findings of this research are summarised as follows:

- Despite the vast software and 0D/1D modelling capabilities, the engine model set-up is considered to be a challenging task. Hence, an in-depth understanding of the engine operation, design and components, as well as the various software capabilities and their corresponding input requirements is essential for developing a reliable engine model.

- The simulated results exhibited sufficient accuracy ( $\pm 3.6 \%$ max. error), thus ensuring the fidelity of the developed 0D/1D engine model.

- The engine power output was found to be the same in both the diesel and DF modes, however the indicated power in gas mode is slightly increased as the higher in-cylinder pressures lead to slightly greater friction power and indicated power. 
- The cylinder compression pressure reduces in the DF mode as both the boost pressure and the air mass flow rate are lower than the respective values of the diesel mode due to the waste gate valve opening, which is utilised to control the air to fuel ratio and hence prevent knocking and misfire.

- To avoid knocking, the pilot injection timing is advanced, the engine compression ratio is lower and the engine was derated (compared to the respective diesel engine version). This leads to an advanced start of combustion, which along with the shorter combustion duration, results in a firing (maximum) pressure significantly higher in the DF mode compared to the diesel mode operation.

- This results in higher engine efficiencies and hence lower $\mathrm{CO}_{2}$ emissions, which are further reduced due to the low carbon to hydrogen ratio of natural gas. The $\mathrm{CO}_{2}$ emissions were found to be $28 \%$ lower on average in DF mode compared to diesel mode. Greater reduction is obtained when the engine operates at the high load region due to the greater difference between the engine efficiency values of the DF and diesel modes.

- The turbocharging unit, matches the engine effectively as it provides sufficient air quantities with high efficiencies at all loads in both operating modes. In the diesel mode, the turbocharger operates close to the maximum speed limit when the engine operates at loads close to $100 \%$ of MCR. However, the waste gate opening control can prevent a potential turbocharger overspeed.

- The NOx emissions were calculated to be on average 97\% lower in the DF mode compared with the diesel mode. The diesel mode complies with the Tier II limits, whereas Tier III limits are met when the engine operates in the DF mode.

- During the engine design phase, it is DF mode that primarily defines the majority of the required engine settings to render the stable engine operation, whilst the diesel mode engine settings are adjusted to achieve the targeted engine NOx emissions limits.

- The parametric study results analysis revealed that a simultaneous further reduction of NOx and $\mathrm{CO}_{2}$ emissions can be obtained if the compression ratio is increased by $5 \%$. However, this cannot be implemented in the current engine version as the compression ratio increase leads to an increased firing pressure, which the engine cannot withstand. However, the increased compression ratio can be an option for future engine versions, in which higher firing pressure can be achieved 
- The NOx- $\mathrm{CO}_{2}$ emission trade-off will be in favour of $\mathrm{NOx}$ emissions by selecting a set of

engine settings where the compression ratio is kept at its reference value.

In conclusion, the present study provides the basis for the engine optimisation and the results contributed to the better understanding of the interplay between the engine settings and the performance -emissions parameters. In this respect, the developed model is proved to be a useful tool that can be employed in the design phase for the marine DF engine development. However, it must be noted that an engine optimisation experimental verification is necessary for finalising the optimal engine settings.

\section{ACKNOWLEDGMENTS}

We would like to deeply thank Messrs. A. Kyrtatos, A. Tomazos, and. G. Volkmar of WinGD for their trust, support and input, which made this work feasible. Gamma Technologies support is greatly acknowledged by the authors.

\section{REFERENCES}

[1] Adams, S. (2014). LNG as ship fuel. The Future - Today, pp.6-7.

[2] International Maritime Organization (2014). MARPOL Annex VI, Regulation 14.

[3] WinGD (2017). Application of WinGD X-DF engines for LNG fuelled vessels.

[4] Kyrtatos, A., Spahni, M., Zuger, R. and Sudwoj, G. (2016). The Development of the Modern LowSpeed Two-Stroke Marine Diesel Engine. In Proceedings of the 28th CIMAC World Congress on Combustion Engine Technology, Helsinki, Finland, 6-10 June 2016; Paper no. 120.

[5] DNV GL (2015). Latest developments and projects in the LNG industry. MARITIME IN FOCUS - LNG AS SHIP FUEL.

[6] Kindt, S. and Sørensen, O. (2016). MAN B\&W Two-stroke Engines Latest design development within engine types, Tier III and multiple gas fuels. In Proceedings of the 28th CIMAC World Congress on Combustion Engine Technology, Helsinki, Finland, 6-10 June 2016; Paper no. 116.

[7] Nylund, I. and Ott, M. (2013). Development of a Dual Fuel technology for slow-speed engines. In: International Council on Combustion Engines. In Proceedings of the 27th CIMAC World Congress on Combustion Engine Technology, Shanghai, China, 13-16 May 2013; Paper no. 284.

[8] Spahni, M., Kyrtatos, A. and Jong, R. (2013). The New X Generation Low-Speed Engines from Wärtsilä. In Proceedings of the 27th CIMAC World Congress on Combustion Engine Technology, Shanghai, China, 13-16 May 2013; Paper no. 267. 
[9] Jaervi, A. (2010). Methane slip reduction in Wartsila lean burn gas engines. In Proceedings of the 26th CIMAC World Congress on Combustion Engine Technology, Bergen, Norway, 14-17 June 2010; Paper no. 106.

[10] Blanke, M. and Anderson, J. (1985). On modelling large two stroke diesel engines: new results from identification. In: IFAC Proceedings Series. pp.2015-2020.

[11] Theotokatos, G. (2010). On the cycle mean value modelling of a large two-stroke marine diesel engine. Proceedings of the Institution of Mechanical Engineers, Part M: Journal of Engineering for the Maritime Environment, 224(3), pp.193-205.

[12] Alegret, G., Llamas, X., Vejlgaard-Laursen, M. and Eriksson, L. (2015). Modeling of a Large Marine Two-Stroke Diesel Engine with Cylinder Bypass Valve and EGR System. IFACPapersOnLine, 48(16), pp.273-278.

[13] Pirker, G., Losonczi, B., Fimml, W., Wimmer, A. and Chmela, F. (2010). Predictive Simulation of Combustion and Emissions in Large Diesel Engines with Multiple Fuel Injection. In Proceedings of the 26th CIMAC World Congress on Combustion Engine Technology, Bergen, Norway, 14-17 June 2010; Paper no. 235.

[14] Scappin, F., Stefansson, S., Haglind, F., Andreasen, A. and Larsen, U. (2011). Validation of a zerodimensional model for prediction of NOx and engine performance for electronically controlled marine two-stroke diesel engines. Applied Thermal Engineering, 37, pp.344-352.

[15] Benvenuto G., Campora U., \& Laviola M. (2013). Simulation Model of a Methane-Fuelled Four Stroke Marine Engine for Studies on Low Emission Propulsion Systems. IMAM 2013, 15th International Congress on Maritime Association of the Mediterranean, 14-17 October 2013. A Corugna,Spain.

[16] Baldi, F., Theotokatos, G. and Andersson, K. (2015). Development of a combined mean valuezero dimensional model and application for a large marine four-stroke Diesel engine simulation. Applied Energy, 154, pp.402-415.

[17] Ozcan, H., \& Yamin, J. (2008). Performance and emission characteristics of LPG powered four stroke SI engine under variable stroke length and compression ratio. Energy Conversion and Management, 49(5), 1193-1201. http://dx.doi.org/10.1016/j.enconman.2007.09.004

[18] Tang, Y., Zhang, J., Gan, H., Jia, B., \& Xia, Y. (2017). Development of a real-time two-stroke marine diesel engine model with in-cylinder pressure prediction capability. Applied Energy, 194, 55-70. http://dx.doi.org/10.1016/j.apenergy.2017.03.015

[19] Grönman, A., Sallinen, P., Honkatukia, J., Backman, J., and Uusitalo, A., (2016). Design and experiments of two-stage intercooled electrically assisted turbocharger. Energy Conversion and Management, 111, pp.115-124.

[20] Coble, A., Smallbone, A., Bhave, A., Mosbach, S., Kraft, M., Niven, P. and Amphlett, S. (2011). Implementing Detailed Chemistry and In-Cylinder Stratification into 0/1-D IC Engine Cycle Simulation Tools. SAE Technical Paper Series 2011-01-0849. doi:10.4271/2011-01-0849. 
[21] Chryssakis, C., Frangopoulos, A. and Kaiktsis, L. (2010). Computational Investigation of InCylinder NOx Reduction in a Large Marine Diesel Engine Using Water Injection Strategies. SAE Technical Paper Series 2010-01-1257. doi:10.4271/2010-01-1257.

[22] Sun, X., Liang, X., Shu, G., Wang, Y., Wang, Y. and Yu, H. (2017). Effect of different combustion models and alternative fuels on two-stroke marine diesel engine performance. Applied Thermal Engineering, 115, pp.597-606.

[23] Wang, B., Li, T., Ge, L., \& Ogawa, H. (2016). Optimization of combustion chamber geometry for natural gas engines with diesel micro-pilot-induced ignition. Energy Conversion and Management, 122, 552-563. http://dx.doi.org/10.1016/j.enconman.2016.06.027

[24] Kyrtatos, N. and Koumbarelis, I. (1994). Performance Prediction of Next Generation Slow Speed Diesel Engines during Ship Manoeuvers. Trans IMarE, pp.1-26.

[25] Theotokatos, G. and Kyrtatos, N. (2003). Investigation of a Large High- Speed Diesel Engine Transient Behavior Including Compressor Surging and Emergency Shutdown. Journal of Engineering for Gas Turbines and Power, 125(2), p.580-589.

[26] Savva, N. and Hountalas, D. (2014). Evolution and application of a pseudo-multi-zone model for the prediction of NOx emissions from large-scale diesel engines at various operating conditions. Energy Conversion and Management, 85, pp.373-388.

[27] Guan, C., Theotokatos, G. and Chen, H. (2015). Analysis of Two Stroke Marine Diesel Engine Operation Including Turbocharger Cut-Out by Using a Zero-Dimensional Model. Energies, 8(6), pp.5738-5764.

[28] Raptotasios, S., Sakellaridis, N., Papagiannakis, R. and Hountalas, D. (2015). Application of a multi-zone combustion model to investigate the NOx reduction potential of two-stroke marine diesel engines using EGR. Applied Energy, 157, pp.814-823.

[29] Wang Z, Zhou S, Feng Y, Zhu Y. (2017) Research of NOx reduction on a low-speed two-stroke marine diesel engine by using EGR (exhaust gas recirculation)-CB (cylinder bypass) and EGB (exhaust gas bypass). International Journal of Hydrogen Energy. 42. 19337-19345. DOI: 10.1016/j.ijhydene.2017.06.009

[30] Cordtz, R., Schramm, J., Andreasen, A., Eskildsen, S. and Mayer, S. (2013). Modeling the Distribution of Sulfur Compounds in a Large Two Stroke Diesel Engine. Energy \& Fuels, 27(3), pp.1652-1660. DOI: 10.1021/ef301793a

[31] Cordtz, R., Mayer, S., Eskildsen, S. and Schramm, J. (2017). Modeling the condensation of sulfuric acid and water on the cylinder liner of a large two-stroke marine diesel engine. Journal of Marine Science and Technology. https://doi.org/10.1007/s00773-017-0455-9

[32] Feng, L., Tian, J., Long, W., Gong, W., Du, B., Li, D. and Chen, L. (2016). Decreasing NOx of a Low-Speed Two-Stroke Marine Diesel Engine by Using In-Cylinder Emission Control Measures. Energies, 9(4), p.304. DOI: 10.3390/en9040304 
[33] Wei, H., Chen, X., Wang, G., Zhou, L., An, S. and Shu, G. (2017). Effect of swirl flow on spray and combustion characteristics with heavy fuel oil under two-stroke marine engine relevant conditions. Applied Thermal Engineering, 124, pp.302-314. https://doi.org/10.1016/j.applthermaleng.2017.05.202

[34] Sun X, Liang X, Shu G, Lin J, Wang Y, Wang Y. (2017) Numerical investigation of two-stroke marine diesel engine emissions using exhaust gas recirculation at different injection time. Ocean Engineering. 144. 90-97. DOI: 10.1016/j.oceaneng.2017.08.044

[35] Pang, K., Karvounis, N., Walther, J., Schramm, J., Glarborg, P. and Mayer, S. (2017). Modelling of temporal and spatial evolution of sulphur oxides and sulphuric acid under large, two-stroke marine engine-like conditions using integrated CFD-chemical kinetics. Applied Energy, 193, pp.60-73.

[36] Kyriakides, N., Chryssakis, C. and Kaiktsis, L. (2009). Influence of Heavy Fuel Properties on Spray Atomization for Marine Diesel Engine Applications. SAE Technical Paper Series.

[37] Goldsworthy, L. (2006). Computational Fluid Dynamics Modelling of Residual Fuel Oil Combustion in the Context of Marine Diesel Engines. International Journal of Engine Research, 7(2), pp.181-199.

[38] Nylund, I. (2007). Field Experience with the Wärtsilä 50DF Dual-Fuel Engine. In: International Council on Combustion Engines. In Proceedings of the 25th CIMAC World Congress on Combustion Engine Technology, Vienna, Austria, 21 - 24 May 2007; Paper no. 239.

[39] Boeckhoff, N., Heider, G. and Hagl, P. (2010). Operational experience of the 51/60 DF from MAN Diesel. In Proceedings of the 26th CIMAC World Congress on Combustion Engine Technology, Bergen, Norway, 14-17 June 2010; Paper no. 37.

[40] Mohr, H. and Baufeld, T. (2013). Improvement of Dual- Fuel-Engine Technology for Current \& Future Applications. In Proceedings of the 27th CIMAC World Congress on Combustion Engine Technology, Shanghai, China, 13-16 May 2013; Paper no. 412.

[41] Ishibashi, R. and Tsuru, D. (2016). An optical investigation of combustion process of a direct highpressure injection of natural gas. Journal of Marine Science and Technology, 22(3), pp.447-458. https://doi.org/10.1007/s00773-016-0422-x

[42] Theotokatos, G., Stoumpos, S., Lazakis, I., \& Livanos, G. (2016). Numerical study of a marine dual-fuel four-stroke engine. In C. G. Soares, \& T. A. Santos (Eds.), Maritime Technology and Engineering III: Proceedings of the 3rd International Conference on Maritime Technology and Engineering (MARTECH 2016, Lisbon, Portugal, 4-6 July 2016). (Vol. 2, pp. 777-783). London. DOI: $10.1201 / \mathrm{b} 21890-100$

[43] Ritzke, J., Andree, S., Theile, M., Henke, B., Schleef, K., Nocke, J. and Hassel, E. (2016). Simulation of a Dual-Fuel Large Marine Engines using combined 0/1-D and 3-D Approaches. In: The International Council on Combustion Engines. In Proceedings of the 28th CIMAC World Congress on Combustion Engine Technology, Helsinki, Finland, 6-10 June 2016; Paper no. 213. 
[44] Sixel, E., Hiltner, J. and Rickert, C. (2016). Use of 1-D simulation tools with a physical combustion model for the development of Diesel-Gas or DF engines. In Proceedings of the 28th CIMAC World Congress on Combustion Engine Technology, Helsinki, Finland, 6-10 June 2016; Paper no. 124.

[45] Moriyoshi, Y., Xiong, Q., Kuboyama, T. and Morikawa, K. (2016). Combustion Analysis in a Natural Gas Engine With Pre-Chamber to Improve Thermal Efficiency. In Proceedings of the 28th CIMAC World Congress on Combustion Engine Technology, Helsinki, Finland, 6-10 June 2016; Paper no. 262.

[46] Yang, L., Song, E., Ding, S., Brown, R., Marwan, N. and Ma, X. (2016). Analysis of the dynamic characteristics of combustion instabilities in a pre-mixed lean-burn natural gas engine. Applied Energy, 183, pp.746-759.

[47] Ott, M. Nylund, I., Alder, R., Hirose, T., Umemoto, Y., \& Yamada, T. (2016). The 2-stroke LowPressure Dual-Fuel Technology: From Concept to Reality. In Proceedings of the 28th CIMAC World Congress on Combustion Engine Technology, Helsinki, Finland, 6-10 June 2016; Paper no. 233.

[48] Mavrelos, C. \& Theotokatos, G. (2017) Modelling and parametric investigation of a large marine two-stroke dual fuel engine, The 11th International Symposium of Marine Engineering (ISME2017), 15-19 Oct 2017, Tokyo, Japan.

[49] WinGD (2017). Application of WinGD X-DF engines for LNG fuelled vessels, Feb 2017. Retrieved from https://www.wingd.com/en/media/papers/application-of-wingd-x-df-engines-forlng-fuelled-vessels/ [Accessed 23 Dec 2017].

[50] WinGD (2015). RT-flex50DF Technical Information-Manuals. Retrieved from https://www.wingd.com/en/products/rt-flex50df/ [Accessed 8 June 2017].

[51] International Maritime Organization (2014). MARPOL Annex VI, Regulation 13.

[52] Gamma Technologies (2016). GT-SUITE Manual.

[53] WinGD (2017) General Technical Data, Program for calculating the performance of WinGD engines, Version 2.2.0.0, 19 Oct 2017. Retrieved from https://www.wingd.com/en/media/generaltechnicaldata/ [Accessed 23 Dec 2017].

[54] Woschni, G., (1967). A Universally Applicable Equation for the Instantaneous Heat Transfer Coefficient in the Internal Combustion Engine (Vol. 76). SAE Technical Paper Series.

[55] Chen, S.K. and Flynn, P. (1965). Development of a Compression Ignition Research Engine. SAE Technical Paper Series. Paper No. 650733.

[56] Ciulli, E. (1993). A review of internal combustion engine losses, pt. 2: studies for global evaluations. Proceedings of the Institution of Mechanical Engineers, Part D: Journal of Automobile Engineering, 207(3), pp.229-240.

[57] Rakopoulos, C.D. and Giakoumis, E.G. (2007). Prediction of friction development during transient diesel engine operation using a detailed model. International Journal of Vehicle Design, 44(1/2), p.143. https://doi.org/10.1504/IJVD.2007.013223 
[58] Karim, G. (2015). Dual-fuel Diesel engines. 1st ed. Boca Raton: CRC Press/Taylor \& Francis Group.

[59] Merker, G.P., Schwarz, C., Stiesch, G., \& Otto, F. (2006). Simulating Combustion. Spinger

[60] Christen, C. and Brand, D. (2013). IMO Tier 3: Gas and dual fuel engines as a clean and efficient solution. In Proceedings of the 27th CIMAC World Congress on Combustion Engine Technology, Shanghai, China, 13-16 May 2013; Paper no. 187.

[61] Sher, E. (1990). Scavenging the two-stroke engine. Progress in Energy and Combustion Science, 16(2), pp.95-124.

[62] Sigurdsson E. (2011) Scavenging Flow in a Two-Stroke Diesel Engine, MSc Thesis. 2 May 2011. DTU. Denmark.

[63] Sigurdsson E, Ingvorsen KM, Jensen MV, Mayer S, Matlok S, Walther JH. (2014) Numerical analysis of the scavenge flow and convective heat transfer in large two-stroke marine diesel engines. Applied Energy. 123. 15. 37-46.

[64] Spicher, U., \& Worret, R. (2002). Klopfkriterium: Vorhaben Nr. 700, Entwicklung eines Kriteriums zur Vorausberechnung der Klopfgrenze; Abschlussbericht: FVV.

[65] Wärtsilä. (2007). Wärtsilä 50DF Engine Technology. Retrieved from https://cdn.wartsila.com/docs/default-source/power-plants-documents/wärtsilä-50df.pdf [Accessed 23 Dec 2017].

[66] Watson, N. and Janota, M. (1986). Turbocharging the internal combustion engine. 1st ed. London [etc.]: MacMillan.

[67] Andre, R. (2013). Dual-Fuel for maritime application. In Proceedings of the 27th CIMAC World Congress on Combustion Engine Technology, Shanghai, China, 13-16 May 2013; Paper no. 204.

[68] Kaltoft, J. and Preem, M. (2013). Development of integrated EGR system for two-stroke diesel engines. In Proceedings of the 27th CIMAC World Congress on Combustion Engine Technology, Shanghai, China, 13-16 May 2013; Paper no. 219.

[69] MAN Diesel \& Turbo. (2011). Basic Principles of Ship Propulsion. MAN Diesel \& Turbo: Augsburg, Germany. No. 5510-0004-02ppr.

[70] CIMAC (2012). EMISSION CALCULATION CHECK GUIDE - IMO NOx Technical Code 2008. The International Council on Combustion Engines, Working Group 'Exhaust Emissions Control' Members. http://www.cimac.com/cms/upload/workinggroups/WG5/CIMAC_Exhaust_Emissions_Control_ Quality_Guide_IMO_NOx_Technical_Code_2008_FINAL.pdf [Accessed 23 Dec 2017].

[71] International Maritime Organisation (2015). MARPOL Annex VI and NTC 2008 with guidelines for implementation.

[72] Hoogerbrugge, R. (2015). General R\&D activities. Presentation, WinGD Licensees' Conference 2015, 6-9 Sep 2015, Interlaken, Switzerland. Retrieved from 
https://www.wingd.com/en/media/presentations/general-rd-activities-r-hoogerbrugge/ [Accessed 23 Dec 2017].

[73] Masuda, Y., Hirose, T., Umemoto, Y., Yamada T. (2017). Innovative Development of Variable Compression Ratio System for Crosshead Type Low Speed Two Stroke Engines. Proceedings of the $11^{\text {th }}$ International Symposium on Marine Engineering (ISME2017). 15-19 October 2017, Tokyo, Japan. 
OD : Zero-dimensional

1D : One-dimensional

3D : Three-dimensional

BMEP : Brake mean effective pressure

BSEC : Brake specific energy consumption

BSFC : Brake specific fuel consumption

CA : Crank angle

CFD : Computational fluid dynamics

$\mathrm{CO}$ : Carbon monoxide

$\mathrm{CO}_{2} \quad$ : Carbon dioxide

$\mathrm{DF} \quad$ : Dual fuel

EGR : Exhaust gas recirculation

EP : Exhaust pipes

EV : Exhaust valve

EVP : Exhaust vale profile

FI : Fuel injector

GI : Gas fuel injector

IMEP : Indicated mean effective pressure

IMO : International maritime organisation

LNG : Liquefied natural gas

MCR : Maximum continuous rating

MVEM : Mean value engine model

NO : Nitric oxide

NOx : Nitrogen oxides

PI : Pilot fuel injector

: Proportional-Integral

PM : Particulate mater

SECA : Sulphur emission control area

SOx : Sulphur oxides

SP : Scavenging ports

TC : Turbocharger

WG : Waste gate

\section{NOMENCLATURE}

$\begin{array}{ll}\mathrm{a}_{\mathrm{kp}} & : \text { model parameter [-] } \\ \mathrm{b}_{\mathrm{kp}} & : \text { model parameter [-] } \\ \mathrm{b} & : \text { model parameter [-] } \\ \mathrm{b}_{\mathrm{k}} & : \text { model parameter [-] } \\ \mathrm{c} & : \text { model parameter [-] } \\ \mathrm{c}_{\mathrm{k}} & : \text { model parameter [-] } \\ \mathrm{exh} & : \text { exhaust gas } \\ \mathrm{FF} & : \text { fraction of fuel per Wiebe curve [-] }\end{array}$




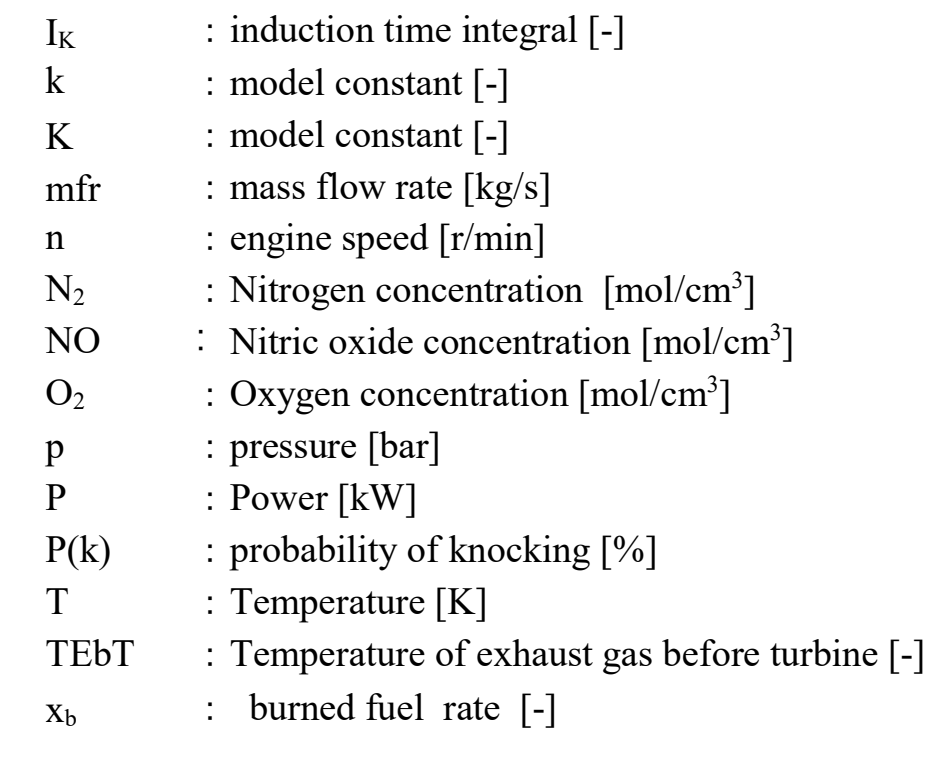

\section{Subscript}

$\begin{array}{ll}1 & : \text { Zone } 1 \\ 2 & : \text { Zone } 2 \\ 50 \mathrm{mfb} & : 50 \% \text { mass fraction burned fuel } \\ 75 \mathrm{mfb} & : 75 \% \text { mass fraction burned fuel } \\ \mathrm{b} & : \text { brake } \\ \text { comp } & : \text { compression } \\ \mathrm{i} & : \text { index number of each Wiebe curve } \\ \max & : \text { maximum } \\ \text { ref } & : \text { reference } \\ \text { scav } & : \text { scavenging }\end{array}$

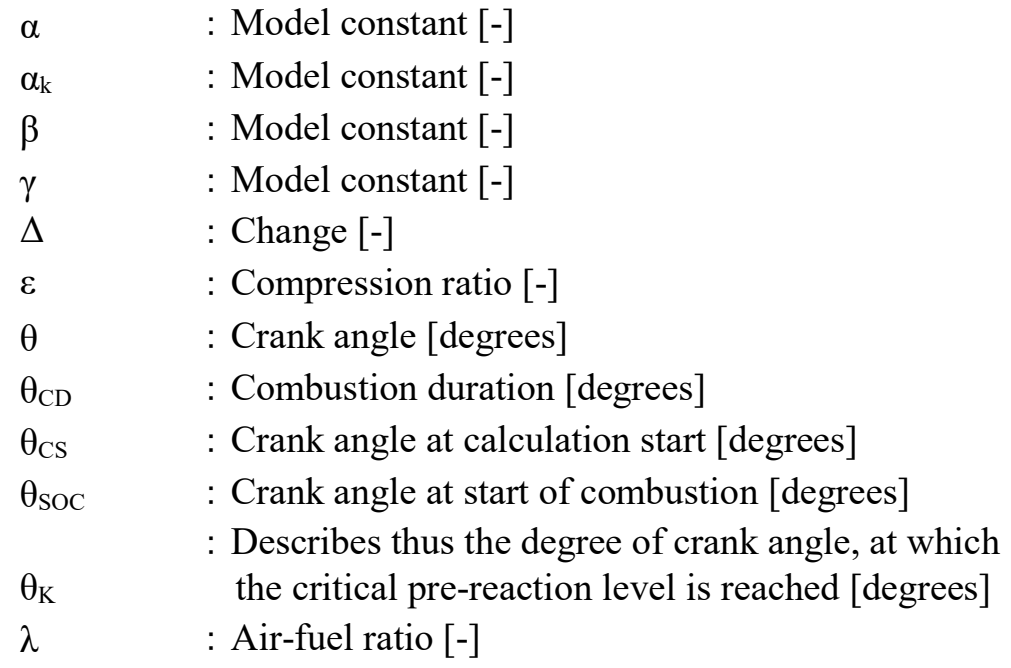

